\title{
Evaluation of Split Thickness Skin Graft Followed by Fractional CO2 Laser in Treatment of Facial Congenital Melanocytic Nevus
}

\author{
TAREK G. SHOUKR, M.D.*; NOHA M. EL-ANWAR, M.D.** and ENGI SEIF E. SHAKER, M.D.** \\ The Department of Plastic Surgery* and Dermatology \& Venereology**, Faculty of Medicine, Tanta University
}

\begin{abstract}
Background: Congenital melanocytic nevi (CMN) have medical, cosmetic and psychological effects on the cases.

Objective: To evaluate the outcome of combined split thickness skin graft (STSG) and fractional CO2 laser in treatment of facial CMN.

Material and Methods: This clinical study was carried out on 8 cases with facial hairy CMN. STSG was harvested from the lateral side of the thigh then 5 sessions with 1 mon apart of fractional CO2 laser was performed after healing.

Results: Eight cases with facial CMN were included in the study; 6 female cases and 2 male cases. The median age was $5.5 y(4-12 y)$. The median follow-up time was 1.5 years (6 month-2y). There was no residual, recurrence nor malignant transformation occurred during the follow-up period. Only one case developed keloid at the site of graft donation and another case developed infection and the healing was delayed. All cases were satisfied. All cases were grade 4 (near total improvement) at the end of the study.

Conclusion: STSG can effectively excise the facial CMN reducing the risk of malignant transformation and followed by fractional $\mathrm{CO} 2$ laser to enhance the cosmetic appearance with minimal complications.
\end{abstract}

Key Words: Congenital melanocytic nevus - Split thickness skin graft - Fractional CO2 laser - Face.

\section{INTRODUCTION}

Congenital melanocytic nevi (CMN) are usually found since birth or occur in $2 \%$ to $3 \%$ of neonates, with $21 \%$ located on the face [1].

CMN's prevalent microscopic observations are nevus cell aggregation up to deep dermis and subcutaneous fat as well as dermal appendages such as hair follicles, sebaceous glands, arrector pili muscles, and neurovascular structures with a relative absence of nevus cells in the subepidermal zone [2].

The nevi are classified divide into small $(<1.5 \mathrm{~cm})$, medium $(1.6-19.9 \mathrm{~cm})$, and large $(>20 \mathrm{~cm})$ [3]. CMN have medical, cosmetic, psychological, and therapeutic implications on the case [4].
The probability of melanoma occurrence is $1 \%$ for small and medium CMN and 5\% for large or giant $\mathrm{CMN}$ with $50 \%$ of transformations occurring before 5 years of age. The second increase of risk of melanoma development within CMN lesions is during adolescence. Considering that most CMN associated melanomas occur during childhood and adolescence, cases with CMN carry an approximate 465-fold increased risk of developing melanoma during this age range [5].

Many treatments for $\mathrm{CMN}$ have been described including chemical peel, cryotherapy, electrocoagulation, excision with primary or secondary closure (e.g. tissue expansion, skin grafts and local flaps) and different types of laser (e.g. CO2, Q-switched Nd:YAG laser). However, many of these techniques involve multiple procedures with a poor final cosmetic result, particularly for giant CMN [6].

Surgical excision remains the mainstay of treatment of CMN especially for medium or large size lesions to decrease the probability of melanoma occurrence with obtaining good cosmoses [5], but scarring and contracture of the scar may affect the cosmetic outcome of surgery [7].

For a long time, many types of lasers have been used for CMN with variable outcome [8]. CO2 laser was used primarily to rejuvenate skin [9]. Laser therapy by fractional $\mathrm{CO} 2$ is one of the most effective treatment options for the resurfacing of the various etiologies. Recent studies have highlighted the importance of early treatment in decreasing scar development by using $\mathrm{CO} 2$ fraction laser [10-12]. After $\mathrm{CO} 2$ laser sessions, various growth factors are released and sequentially cytokines are generated with varying concentrations over time which leads to the coordinated expression of heat shock proteins, matrix metalloproteinases, growth factors and other mediators which are vital for early epidermal regrowth and collagen remodeling [13,14]. 
The aim of this study was to evaluate the outcome of split thickness skin graft (STSG) followed by fractional $\mathrm{CO} 2$ laser in treatment of facial CMN.

\section{PATIENTS AND METHODS}

This clinical study was carried out in Tanta University Hospitals in Plastic Surgery Department and Dermatology \& Venereology Department from January 2016 to April 2019 on 8 cases, aged less than 18 years old, both genders, with facial hairy congenital melanocytic nevus and parents' counseling indicated that the lesion was affecting the school and social activities of the children.

An informed written consent was obtained from all cases' guardians. Separate consent for photography was taken. Every case's guardians received an explanation to the purpose of the study and would have a secret code number to ensure privacy to participants and confidentiality of data. Research results were only used for scientific purposes. Any unexpected risk appeared during the course of the research cleared to the participants and ethical committee on time and proper measures were taken to overcome or minimize these risks.

Exclusion criteria were case's guardian refusal to participate, other satellite lesions present over the body, other congenital anomalies, systemic diseases or drugs that may affect healing, coagulopathy, atypical cells in the histopathology.

Preoperative evaluation included history, physical examination, laboratory investigations (CBC, bleeding profile (prothrombin time, INR), liver function tests, renal function tests, and echocardiography).

\section{Surgical technique:}

All areas needed to be excised were infiltrated with tumescent solution (adrenaline 1/200.000). Excision was dons up to the subcutaneous plane. A single-stage complete excision of the nevus under general anesthesia was done then STSG was harvested from the lateral side of the thigh. Subsequently, the resulting defect was covered with the STSG by securing at the edge of the defect with 4.0 PDS sutures. In the process, meticulous hemostasis was acquired by selective electrocoagulation in the excised area and immobilization of the graft was performed postoperatively by tie-over sutures. The operative sites of all cases were dressed in wet cotton bolsters and subsequently wrapped with elastic bandages. All cases received prophylactic antibiotics (first generation Cephalosporin) postoperatively. The excised specimen was sent to histopathology to exclude the malignancy.
After healing (about one month after the operation), fractional $\mathrm{CO} 2$ laser was performed on treated area (SmartXide- Deka), every case received 5 sessions with 1 month apart. The laser parameters were as follow (15 watt, 500 microseconds dwell time, 700 micrometer spacing). Cases were followedup for at least 6 months after the last laser session.

The characteristics of wound care and healing was noted. Preoperative and postoperative digital photographs were taken for all cases to evaluate the long-term outcomes through follow-up. Case's guardian satisfaction was assessed by 5 -point scale (with 1 being "absolutely dissatisfied", 2 being "dissatisfied", 3 being "neither dissatisfied nor satisfied", 4 being "satisfied" and 5 being "absolutely satisfied").

Clinical response was scored using a quartile grading scale as follows: Grade $1(0 \%-25 \%)=$ minimal to no improvement, grade $2(26 \%-50 \%)$ $=$ moderate improvement, grade $3(51 \%-75 \%)=$ marked improvement, and grade 4 (more than $75 \%$ ) $=$ near total improvement.

The collected data were statistically analyzed using SPSS (IBMC), USA) version 25. Quantitative data were described as median and range (as data had nonparametric distribution) and qualitative data were presented as number and percentage.

\section{RESULTS}

Eight cases with facial CMN were included in the study; six (75\%) female cases and two $(25 \%)$ male cases. The median age was 5.5 years; ranging from 4 to 12 years. The location and size of the lesions are as shown in Table (1). Fitzpatrick skin type was 2 in $2(25.0 \%)$ cases, 3 in $3(37.5 \%)$ cases and 4 in $3(37.5 \%)$ cases. CMN was found since birth in all cases.

The histopathologic examination of the excised specimen showed no evidence of melanoma in all cases. Also, there was no residual, recurrence nor malignant transformation occurred during the follow-up period. Only one case developed keloid at the site of graft donation and another case developed infection and the healing was delayed (therefore, this case was less satisfied than others). All cases were satisfied. All cases were grade 4 (near total improvement) at the end of the study.

The median follow-up time was 1.5 years (range from 6 months to 2 years). The follow-up outcome of all cases revealed that all of them got acceptable cosmetic and functional results. Skin discrepancy between the graft and nearby skin was minimal at the end. 


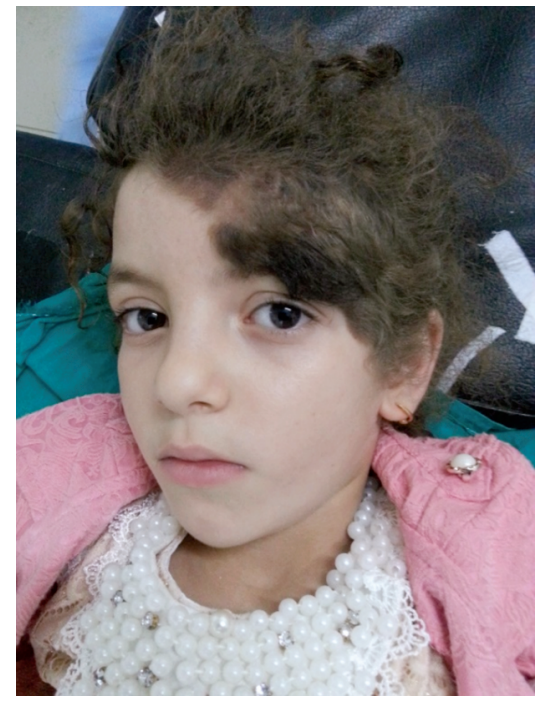

(A) Before surgery.

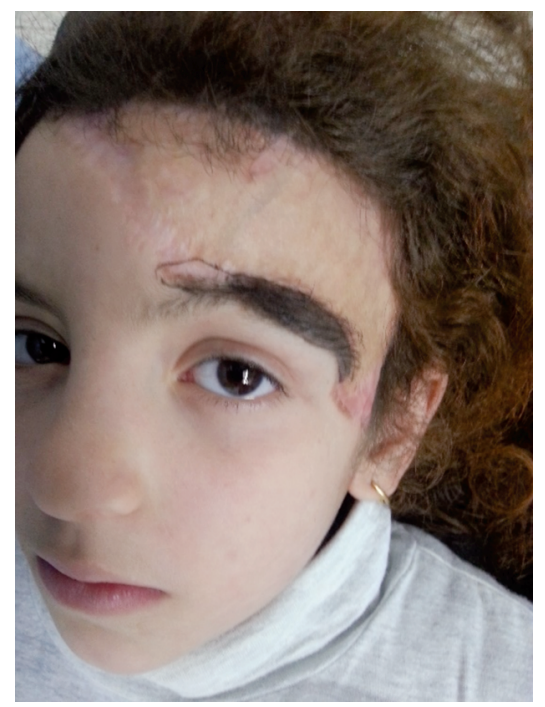

(C) After $2^{\text {nd }}$ session.

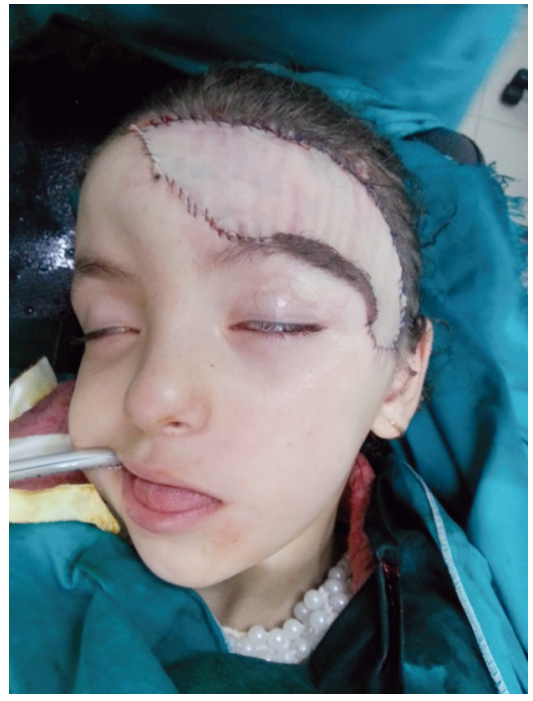

(B) Intraoperative.

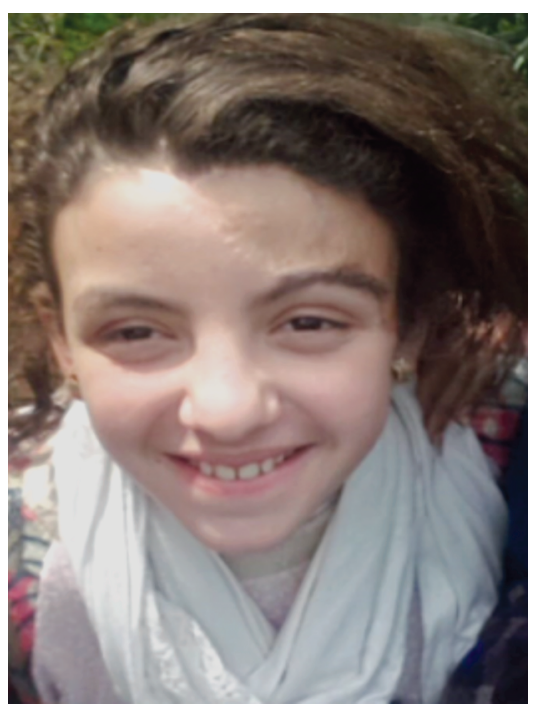

(D) After 5 sessions.

Fig. (1): Case number 1 (A) Before surgery (B) Intraoperative (C) After 2nd session (D) After 5 sessions.

Fig. (2): Two years after surgery of case number 1 .

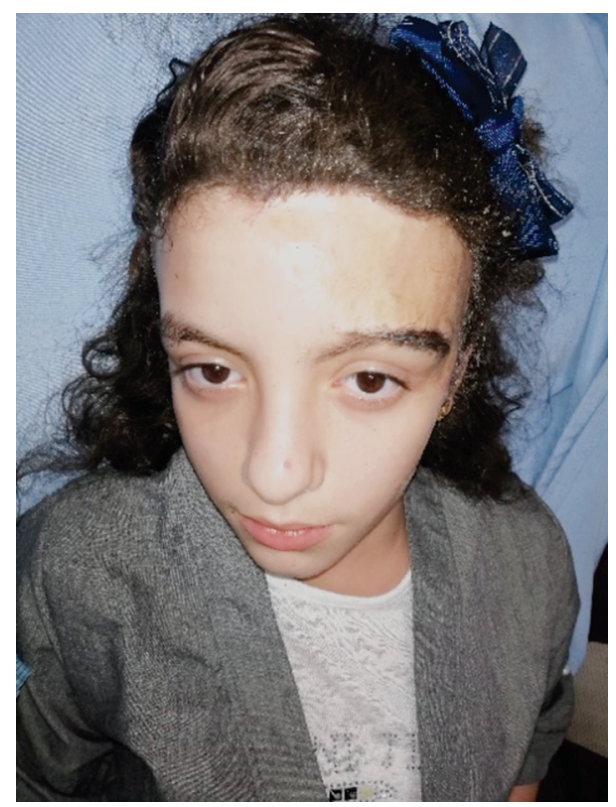


Table (1): Patients details.

\begin{tabular}{|c|c|c|c|c|c|c|c|c|c|c|c|}
\hline $\mathrm{N}$ & $\begin{array}{l}\text { Age } \\
\text { (y) }\end{array}$ & Gender & $\begin{array}{c}\text { Fitzpatrick } \\
\text { Skin type }\end{array}$ & Onset & Site & $\begin{array}{l}\text { Size } \\
\left(\mathrm{cm}^{2}\right)\end{array}$ & $\begin{array}{l}\text { Compli- } \\
\text { cations }\end{array}$ & $\begin{array}{l}\text { Satis- } \\
\text { faction }\end{array}$ & $\begin{array}{l}\text { Follow- } \\
\text { up }\end{array}$ & $\begin{array}{c}\text { Histo- } \\
\text { pathology }\end{array}$ & $\begin{array}{c}\text { Quartile } \\
\text { scale }\end{array}$ \\
\hline 1 & 7 & Female & 2 & Since birth & $\begin{array}{l}\text { Left part of the fore- } \\
\text { head and left tem- } \\
\text { poral area reach } \\
\text { left eyebrow }\end{array}$ & $4 * 7$ & - & 5 & $2 y$ & Benign & 4 \\
\hline 2 & 8 & Female & 3 & Since birth & $\begin{array}{l}\text { Right part of the } \\
\text { forehead and right } \\
\text { temporal area } \\
\text { reach right eye- } \\
\text { brow }\end{array}$ & $5 * 8$ & - & 5 & $1.5 \mathrm{y}$ & Benign & 4 \\
\hline 3 & 4 & Female & 4 & Since birth & $\begin{array}{l}\text { Central part of the } \\
\text { forehead and } \\
\text { reach medial part } \\
\text { of both eyebrow }\end{array}$ & $3 * 6$ & - & 5 & $1 \mathrm{y}$ & Benign & 4 \\
\hline 4 & 4 & Male & 2 & Since birth & $\begin{array}{l}\text { Central part of the } \\
\text { forehead }\end{array}$ & $4 * 3.5$ & $\begin{array}{l}\text { Infection and } \\
\text { d e l a y e d } \\
\text { healing }\end{array}$ & 4 & 1.5 & Benign & 4 \\
\hline 5 & 12 & Male & 4 & Since birth & $\begin{array}{l}\text { Left temporal area } \\
\text { reach left eye- } \\
\text { brow }\end{array}$ & $3 * 3.5$ & - & 5 & 9 mon & Benign & 4 \\
\hline 6 & 6 & Female & 3 & Since birth & $\begin{array}{l}\text { Left temporal area } \\
\text { reach left eye- } \\
\text { brow }\end{array}$ & $2.5^{* 4}$ & $\begin{array}{l}\text { Keloid at do- } \\
\text { nor area }\end{array}$ & 5 & 6 mon & Benign & 4 \\
\hline 7 & 5 & Female & 3 & Since birth & $\begin{array}{l}\text { Right temporal area } \\
\text { reach right eye- } \\
\text { brow }\end{array}$ & $3 * 4$ & - & 5 & 2 mon & Benign & 4 \\
\hline 8 & 5 & Female & 4 & Since birth & $\begin{array}{l}\text { Right temporal area } \\
\text { and reach right } \\
\text { eyebrow }\end{array}$ & $2.5 * 3$ & - & 5 & $1.5 \mathrm{y}$ & Benign & 4 \\
\hline
\end{tabular}

\section{DISCUSSION}

To our knowledge, this is the first time to use fractional CO2 laser after STSG in treatment of facial CMN. In the present study, we used this combination to get the benefits of both surgical excision (to reduce the risk of melanoma transformation) and fractional $\mathrm{CO} 2$ laser (to get better cosmetic result).

Over the first year of life, surgical treatment is recommended to be done before school age. Nevertheless, it is not uncommon to find people later in their lives, which renders the reconstruction even more complicated [15].

The long-term recurrences with laser treatments cannot be excluded because of the lack of penetration to deeper levels of tissue. Moreover, the risk of developing melanoma after laser treatment is still questionable; therefore, surgical excision is preferred.
The lasers investigated for the treatment of CMN include pigment-specific lasers [ruby $(694 \mathrm{~nm})$, alexandrite $(755 \mathrm{~nm}), \mathrm{Nd}$ : yttrium aluminum garnet (YAG) $(1064 \mathrm{~nm})]$ and ablative laser treatment [CO2 laser $(10,600 \mathrm{~nm})$ and Er: JAG $(2940 \mathrm{~nm})]$ [8]. The new in our study is the use of fractional $\mathrm{CO} 2$ laser in esthetic role not in ablation.

Resurfacing lasers are a less possible treatment option for pigmented wounds since the advent of Q-switched (QS) lasers. The use of CO2 laser is well established in the diagnosis of epidermal nevi and Becker's immune nevi. Nevertheless, the issue of underlying cicatrisation and hypopigmentation makes it less appealing. QS lasers are not always successful, and they have poor success levels, particularly for thicker and/or hairy CMNs.

The literature has documented $\mathrm{CO} 2$ lasers with or without additional QS laser treatment for CMNs with variable outcomes [16]. 
Dai et al. [17] study enrolled large and giant CMN underwent surgical excision of these lesions and closured the defects with full-thickness skin grafts (FTSK) harvested from the lower abdomen. These lesions were located on the face $(30 \%)$, neck (20\%), elbow (20\%), hand (15\%), knee (5\%), foot $(10 \%)$. Multiple small remaining defects were treated with STSG harvested from thigh. Hypertrophic scarring occurred at the edges of the graft in 3 cases.

El-Sabbagh [18] studied 16 cases; 9 cases were in the face. Lesions were excised according to the esthetic subunits of the face. FTSK was utilized to rebuild the periorbital region and the lateral wall of nose with in combination with STSG. There was no malignancy transformation nor recurrence observed.

Goil et al. [15] retrospective study was performed in 17 people above 14 years of age seeking surgical treatment of giant face CMN. Tissue expansion (TE), STSG, FTSK, and free tissue transfer (FTT) were the primary reconstructive procedures and 15 people had to undergo additional operations. Esthetic outcomes were superior with TE and FTT. Partial loss of STSG required secondary grafting, which healed with hyperpigmentation and secondary contracture. Partial loss of FTSG has been only treated conservatively with dressings.

Infection occurred in one case and was treated by antibiotics. Donor-site morbidity in the form of scarring and contour deformities were present in all cases of FTT and did not require intervention. Aesthetic outcome was moderate to good.

Horner et al. [6] reviewed 12 cases retrospectively with $\mathrm{CMN}$ treated with $\mathrm{CO} 2$ laser for ablation (A continuous-wave $\mathrm{CO} 2$ laser beam was administered from a Sharplan 40C or a Nidek Unipulse 1040 CO2 laser machine). In all cases, there was minimal visible nevus after treatment. Hypertrophic scarring occurred in 6 cases $(73 \%)$ of the treatments on the anterior torso, flanks, and arms and in none of the cases treating the back or buttocks. They didn't include the face.

Downs and $\mathrm{Ng}$ [16] presented 3 cases of facial CMN; two were periocular. One had failed four treatments of a QS 532nm Nd: YAG laser and partial cleared with one $\mathrm{CO} 2$ treatment; and the other, which responded completely to a single $\mathrm{CO} 2$ treatment. The third case had the lesion located on the tip of the nose. No case scarred or hypopigmented. In general, the nose and periocular areas are very forgiving of $\mathrm{CO} 2$ laser treatments. Treating CMNs in these areas with the $\mathrm{CO} 2$ laser should be a valid treatment option, although outcomes can vary.

Kishi et al. [19] treated 9 cases with mediumsized to giant $\mathrm{CMN}$ on the face or upper limbs from 1 month of age with early serial Q-switched ruby laser therapy. Sessions needed to make the color similar to the nearby skin were $8-15$. The mean number of treatments was 9.6. In all cases, the color was decreased to $0-20 \%$. In eight cases, partial slight repigmentation occurred. These nevi were treated with one or two more Q-switched ruby laser irradiations and lightened successfully at least 1 year. Pigmentation returned to the same level as the original lesion in the remaining cases within 1 month of last therapy. The lesion was therefore excised for cosmetic reasons. At the end, the texture of the skin was fine and there was no hypertrophic scar.

Hong et al. [20] enrolled 6 cases with mediumto-giant CMN and treated them with combined Er: YAG and long pulsed-Alex lasers at an interval of 9-12 weeks. After 1.83 sessions, all medium CMN showed good to excellent pigment removal. After a single treatment, giant CMN showed good pigment extraction. There have been no serious changes in skin, hypertrophic scars or depigmentation. Moderated hypertrophic scar was found in one case; one case had mottled hypopigmentation and two cases reported persistent erythema, which decreased with additional LPDL. Repigmentation or malignancy were not observed in the 2-9-month follow-up (short period).

Lee et al. [21] treated 7 small CMN cases with Er: YAG laser followed by long-pulsed alexandrite laser at 1-mon intervals for 2 mon. Duration of follow-up was 6 mon. All treated nevi showed total pigment removal and a medical doctor's average overall improvement score with a quartile grading scale of 3.6 \pm 0.7 . For one scenario, chronic erythema was observed but healed without further treatments. Hypertrophic scar occurred in one case, mild atrophic skin texture occurred in one case and recurrence of pigmentation occurred in one case during the follow-up. Further studies are needed to compare surgery, laser and combined surgery and laser with longer follow-up.

\section{Conclusion:}

STSG can effectively excise the facial CMN reducing the risk of malignant transformation and followed by fractional $\mathrm{CO} 2$ laser to enhance the cosmetic appearance with minimal complications.

Conflicts of interest: Nil. 


\section{REFERENCES}

1- Viana A.C.L., Gontijo B. and Bittencourt F.V.: Giant congenital melanocytic nevus. An Bras Dermatol., 88: 863-78, 2013.

2- Everett M.A.: Histopathology of congenital pigmented nevi. Am. J. Dermatopathol., 11: 11-2, 1989.

3- Price H.N. and Schaffer J.V.: Congenital melanocytic nevi-when to worry and how to treat: Facts and controversies. Clin. Dermatol., 28: 293-302, 2010.

4- Ruiz-Maldonado R.: Measuring congenital melanocytic nevi. Pediatr. Dermatol., 21: 178-9, 2004.

5- Fahradyan A., Wolfswinkel E.M., Tsuha M., Reinisch J.F., et al.: Cosmetically Challenging Congenital Melanocytic Nevi. Ann. Plast. Surg., 82: S306-s9, 2019.

6- Horner B.M., El-Muttardi N.S. and Mayou B.J.: Treatment of congenital melanocytic naevi with $\mathrm{CO} 2$ laser. Ann. Plast. Surg., 55: 276-80, 2005.

7- Sardana K., Chakravarty P. and Goel K.: Optimal management of common acquired melanocytic nevi (moles): Current perspectives. Clin. Cosmet Investig. Dermatol., 7: 89-103, 2014

8- Bray F.N., Shah V. and Nouri K.: Laser treatment of congenital melanocytic nevi: A review of the literature. Lasers Med. Sci., 31: 197-204, 2016.

9- Omi T. and Numano K.: The Role of the CO2 Laser and Fractional CO2 Laser in Dermatology. Laser Ther., 23: 49-60, 2014.

10- Du F., Yu Y., Zhou Z., Wang L., et al.: Early treatment using fractional $\mathrm{CO} 2$ laser before skin suture during scar revision surgery in Asians. J. Cosmet Laser Ther., 20: 102-5, 2018.

11- Majid I. and Imran S.: Efficacy and Safety of Fractional CO2 Laser Resurfacing in Nonhypertrophic Traumatic and Burn Scars. J. Cutan Aesthet. Surg., 8: 159-64, 2015.

12- Choi J.E., Oh G.N., Kim J.Y., Seo S.H., et al.: Ablative fractional laser treatment for hypertrophic scars: Compar- ison between Er:YAG and CO2 fractional lasers. J. Dermatolog. Treat., 25: 299-303, 2014.

13- DeBruler D.M., Blackstone B.N., Baumann M.E., McFarland K.L., et al.: Inflammatory responses, matrix remodeling, and re-epithelialization after fractional CO2 laser treatment of scars. Lasers Surg. Med., 49: 675-85, 2017.

14- Shumaker P.R., Kwan J.M., Badiavas E.V., Waibel J., et al.: Rapid healing of scar-associated chronic wounds after ablative fractional resurfacing. Arch. Dermatol., 148: 1289-93, 2012.

15- Goil P., Jain A., Patil A.N., Singh A., et al.: Surgical management of giant congenital melanocytic nevus of face in the adult-outcomes and experience. Eur. J. Plast. Surg., 41: 529-34, 2018.

16- Downs A., Ng S., editors.: CO2 laser treatment for facial congenital melanocytic nevi. J. Am. Acad. Dermatol., Mosby-elsevier 360 Park Avenue South, New York, NY 10010-1710 USA, 2008

17- Dai T., Zhang S., Ren Y., Liu L., et al.: Clinical effect of full-thickness skin grafts for the treatment of large and giant congenital melanocytic nevus on the face and extremities joints in children. Int. J. Clin. Exp. Med., 9: 5609-15, 2016.

18- El-Sabbagh A.H.: Is there still a place for skin graft in giant congenital melanocytic nevus? Eur. J. Plast. Surg., 41: 177-82, 2018.

19- Kishi K., Okabe K., Ninomiya R., Konno E., et al.: Early serial Q-switched ruby laser therapy for medium-sized to giant congenital melanocytic naevi. Br. J. Dermatol., 161: 345-52, 2009.

20- Hong K.T., Lim J.M. and Lee S.E.: A Treatment of Medium-to-Giant Congenital Melanocytic Nevi with Combined Er: YAG Laser and Long-Pulsed Alexandrite Laser. Medical Lasers, 6: 77-85, 2017.

21- Lee S.E., Choi J.Y., Hong K.T. and Lee K.R.: Treatment of acquired and small congenital melanocytic nevi with combined Er: YAG laser and long-pulsed alexandrite laser in Asian skin. Dermatol. Surg., 41: 473-80, 2015. 